\title{
LA RECEPCIÓN DEL POSITIVISMO Y DEL EVOLUCIONISMO EN ESPAÑA Y "EL PROBLEMA DE LA MUJER"1
}

\author{
María José Tacoronte Domínguez ${ }^{2}$
}

Resumen: "La cuestión de la mujer" toma mayor relevancia tras la recepción del positivismo y el evolucionismo en las ciencias médicas y biológicas españolas, sobre todo a finales del siglo XIX y los inicios del Siglo XX. La finalidad de estas teorías, en un contexto donde la ciencia gozaba de gran autoridad, era justificar la inferioridad mental y biológica de las mujeres. El presente artículo trata de mostrar las consideraciones de los médicos españoles acerca de la naturaleza inferior femenina, tras la influencia de los científicos europeos, y de mostrar, a su vez, las voces disidentes de las pensadoras que se opusieron a las mismas.

Palabras clave: Ciencia, Positivismo, Inferioridad, Mujer y Feminismo.

Title in English: The Reception of Positivism and Evolutionism in Spain and "The Woman Question"

Abstract: "The Woman Question" acquires major significance in the wake of the influence of positivism and evolutionism on Spanish medical and biological sciences, particularly in the latenineteenth and early-twentieth centuries. In the context of the overriding authority of science, the objective of these theories was to justify a biological and mental inferiority of women. This paper will attempt to show the mindset of the Spanish scientists who, influenced by European theories, viewed women's nature as inferior. It will also reflect on the dissenting voices of thinkers who took an opposite view on the same subject.

Keywords: Science, Positivism, Inferiority, Women and Feminism.

Los caracteres tipológicos y fisiológicos del hombre

Adulto normal, prueban que la mujer es un organismo

retenido en un estado de permanente infantilización.

Roberto Novoa Santos.

(La mujer nuestro sexto sentido y otros esbozos, 1929)

\footnotetext{
${ }^{1}$ Fecha de recepción: 29/07/10

Fecha de aceptación: 06/10/2013

Este trabajo se ha realizado en el marco del proyecto de investigación, Política de la ciencia, institucionalización y epistemología en la constitución de un contrato social para la ciencia en España, 1900-1968. Año: 2013-2015. FFI2012-33998.

${ }_{2}$ Becaria de Investigación, Departamento de Historia y Filosofía de la Ciencia, la Educación y el Lenguaje, Universidad de La Laguna, España; $\bowtie$ mjtacorontedominguez@gmail.com.
} 
La España de finales del siglo XIX e inicios del XX estuvo dominada por el debate intelectual que supuso la recepción de ciertas corrientes científicas y filosóficas. Entre ellas destacó la recepción del evolucionismo y el positivismo, que cuestionaban tanto al liberalismo metafísico de los krausistas como al pensamiento católico. Estas corrientes tuvieron un considerable componente progresista que, sin embargo, se quebraba en lo referente al tratamiento de la que se denominó "la cuestión de las mujeres". Esta cuestión se traducía en el intento de desarrollar una fundamentación cientifista de los estereotipos de género utilizando como recurso legitimador la inferioridad de la naturaleza femenina. El debate acerca de la naturaleza femenina, que se venía desarrollando en otros países europeos, supuso un difícil reto para las tesis igualitaristas y especialmente para el incipiente pensamiento feminista español que, además de tener que contender con el pensamiento conservador y religioso, vio como se le abría un nuevo frente desde la ciencia.

El objetivo de este artículo es mostrar el importante papel ideológico que tuvieron el positivismo y el evolucionismo como recursos que fundamentaron los estereotipos de género, cuál fue la recepción de este programa en España y cómo lo encaró el incipiente pensamiento feminista español.

\section{La Misoginia Científica}

A finales del siglo XIX se planteó en España el denominado "problema de la mujer" en el contexto de la recepción del evolucionismo y positivismo por las élites científicas e intelectuales. A esta cuestión se dedicaron muchos escritos, artículos y libros, en los que se expusieron diferentes hechos del cuerpo, su biología y anatomía 
que, a juicio de los científicos, "demostraban" la inferioridad femenina ${ }^{3}$. Este "problema" siguió debatiéndose a lo largo del siglo XX y ha llegado hasta nuestro presente bajo diferentes formulaciones.

La recepción del positivismo en España estuvo marcada por dos impulsos claros: de un lado, el ansia imperante de progresar, abriéndose a las corrientes de pensamiento europeas y, de otro, la voluntad de apoyarse en los nuevos planteamientos "positivos" en la búsqueda de soluciones para los problemas apremiantes del país. El creciente auge del recurso al método científico en el estudio de la sociedad influyó en la idea de que todo problema debía ser tratado "científicamente" y, por tanto, también "el problema de la mujer". En este sentido, las tesis evolucionistas fascinaban a los científicos y parecían capaces de explicar científicamente la evolución humana y las diferencias entre sexos, clases sociales y razas.

Los estudios que se venían realizando sobre la naturaleza femenina se basaban en la observación sistemática, los registros, las clasificaciones, las comparaciones y la inducción, a partir de los datos ${ }^{4}$. La concepción de la mujer que estaba operando en el trasfondo de estos estudios seguía siendo básicamente la que había dominado en la cultura occidental, ahora reformulada desde una óptica científica, y cientifista, que pretendía explicar los hechos naturales que determinaban la inferioridad de las mujeres a partir precisamente de "su naturaleza diferente". A grandes rasgos, la mujer tenía una naturaleza diferente a la del hombre y esta diferencia se entendió y justificó como inferioridad física, intelectual e, incluso, moral. La teoría de la evolución explicaba por qué las mujeres eran menos evolucionadas que los hombres y por qué había evolucionado sólo hasta estadios inferiores, igual que las razas no blancas. Esta explicación se basó en las funciones naturales de la mujer, para las que no era necesario un mayor desarrollo de la hembra humana, al contrario de lo que ocurría con los hombres. La adaptación al medio de las mujeres no requería de un desarrollo de sus capacidades mentales y físicas en el mismo grado que en el caso de los hombres. El

\footnotetext{
3 A modo de ejemplo, véase: Alarcón y Meléndez (1908); Novoa Santos (1908); Gimeno de Flaquer (conferencia: "El problema Feminista"); González Blanco (1905); Nuestro Tiempo 61, Vol. III.: 12-35; De la Revilla (1879); Revista Contemporánea. Año III-IV. Tomo XVIII.: 447-463.

${ }^{4}$ A modo de ejemplo: Gall (1810-1819) y Spencer (1850).
} 
modelo de evolución era claramente el hombre, el varón de la especie, culminando la perfección evolutiva en el varón caucásico occidental.

La mujer en España había sido concebida por la ortodoxia católica como portadora de cualidades morales y emocionales, propias de su sexo, que eran entendidas y propuestas, inclusive, como superiores a las del hombre. La mujer era la encargada de guiar el ámbito privado y cuidar a la prole. Por ello, la tradición católica le atribuía una alta moral de entrega y sacrificio de la que carecían los varones. Las mujeres quedaban recluidas en el ámbito familiar y privado que les era propio, mientras la esfera pública era en exclusiva el terreno de los varones.

El viraje procedente de la instauración de la ciencia como fuente privilegiada de legitimación de las relaciones entre los sexos, y de determinación del ámbito que les era propio por naturaleza, vino a ratificar la división entre los sexos de la esfera privada y pública y a naturalizar las cualidades femeninas que la religión había otorgado a las mujeres. Las mujeres eran ahora recluidas en el entorno privado por la ciencia, que se limitaba a mostrar científicamente los hechos que hacían inferiores a las mujeres y que les impedía acceder al conocimiento, el trabajo o el gobierno.

\section{La mujer según el positivismo y el evolucionismo español}

El enfoque científico de la inferioridad de las mujeres se introdujo en España a través de la recepción de los trabajos de importante científicos europeos, sobre todo médicos, como Moebius, Max Nordau, Lombroso, Otto Weiniger, o Spencer. Todos ellos compartían la idea de que las diferencias anatómicas, fisiológicas, biológicas y, por tanto, evolutivas, entre hombres y mujeres eran claves para explicar la inferioridad de la mujer. Estas tesis encontraron en España dos férreos seguidores, que siguieron al pie de la letra las teorías evolucionistas y el enfoque positivista imperante en las ciencias del momento: los médicos Roberto Novoa Santos y Edmundo González 
Blanco $^{5}$. Para ambos científicos la mujer había sido mal representada en los textos y en la conciencia colectiva, porque "puede decirse que la mujer aparece en la filosofía de todos los pueblos, no como es en realidad, sino tal como se le figura a un entusiasta enamorado" (Nordau, en Novoa Santos 1908: 116). Contra esta idea generalizada entre los hombres de ciencia, los trabajos de estos médicos se encaminaban a demostrar, mediante los hechos y los datos, la indigencia espiritual y mental de las mujeres.

Novoa y González Blanco fueron grandes conocedores de los estudios realizados en Europa por los frenólogos que se encargaban de recopilar y comparar datos sobre el cráneo y el peso, volumen y circunvalaciones del cerebro en investigaciones racistas y sexistas $^{6}$. Ambos se apropiaron de los argumentos de antropólogos físicos, frenólogos y psicólogos diferenciales en contra de la igualdad entre hombres y mujeres. Roberto Novoa Santos comentaba que: "Parece, pues, que con independencia del estado social de los distintos pueblos, la capacidad de la cápsula craneal de la hembra es siempre inferior a la del macho" (Novoa Santos 1908: 38). Estaba de acuerdo, pues, con los trabajos de Retzius y Broca acerca del volumen y peso del cerebro. El peso medio del cerebro del varón se estableció en unos 1425 gramos, y el correlativo de la mujer en 1222 gramos. De esta diferencia de 200 gramos se derivaba la superioridad intelectual de los hombres. Por otro lado, ambos médicos aceptaban que el cerebro era el órgano de la mente y que las facultades mentales estaban situadas en órganos cerebrales específicos. Por tanto, el peso y volumen del cerebro indicaban el grado en que se poseían tales facultades.

A estos argumentos se sumaron los de tipo fisiológico y anatómico. Cualquier dato era interpretado y establecido como prueba de la inferioridad femenina. La menstruación no escapó a los análisis de muchos misóginos de la ciencia. Novoa Santos, entre otros, defendía que el flujo menstrual de la mujer la inhabilitaba para desarrollar muchas actividades, como por ejemplo estudiar, ejercer como juez, ministro, etc., ya que su estado anímico es muy voluble y no le permite atender con claridad a las cuestiones de rigor y de gran interés que requieren estas actividades, véase Mariscal y

\footnotetext{
${ }^{5}$ Como muestra véase: Novoa Santos (1908) y González Blanco (1905).

${ }^{6}$ Como decíamos, eran seguidores de las teorías de Gall, su discípulo Johann Spurzheim, Max Nordau, Cesare Lombroso, Otto Weininger, entre otros.
} 
García (1898). Novoa defendió además que la mujer tenía mayor sensibilidad táctil que el hombre y, por ende, tenía menor poder para inhibir el dolor, lo cual la hacía más vulnerable al entorno y dependiente de éste (Novoa Santos 1908: Cap. III). Con este planteamiento, Novoa invertía los términos de la argumentación del científico italiano Lombroso para llegar a la misma conclusión. Para Lombroso las mujeres estaban constituidas por una sensibilidad ruda y vulgar, estandarizada y similar a la de los animales; en cambio, el hombre era más sutil en sus percepciones sensitivas, rasgos indiscutibles de su superioridad evolutiva y de su adaptación, cada vez mejor, al medio que lo rodeaba. Esta discrepancia revela cómo se reformulaban las tesis, y cómo se usaban datos contrapuestos para fundamentar la inferioridad de las mujeres. En definitiva, las cualidades físicas se redefinían de acuerdo a criterios interesados acerca de aquéllas ${ }^{7}$.

En este contexto se trajo a colación la relación entre la función sexual y la actividad cerebral. El aparato genital representaba una función primordial (y determinista) en el organismo femenino. De hecho, su naturaleza estaba encaminada a la concepción y a la reproducción de la especie. Médicos y evolucionistas coincidían en afirmar que la energía femenina tenía como objetivo la reproducción y crianza del debido número de niños sanos: "Spencer consideraba que si las mujeres desarrollaban cualidades mentales superiores provocarían la desaparición de la sociedad; en cuanto dejasen de emplear toda su energía en la que es su función natural (la procreación), la especie se resentiría, degeneraría y perdería parte de sus más altos logros evolutivos" (Gómez Rodríguez 2004: 56). Esta función básica de la mujer disminuiría si sus esfuerzos se orientaban a la educación o al trabajo, y no a su destino biológico-natural, como señalaban una y otra vez los evolucionistas y sus seguidores españoles. Novoa Santos ponía el ejemplo de una mujer joven que estudiaba y que perdió el flujo periódico a consecuencia de ello; bastó con quitarle sus libros y novelas para que se

\footnotetext{
${ }^{7}$ En este punto la endocrinología y la bioquímica, además de la influencia de las teorías evolucionistas, dieron lugar a mayores cotas de inferioridad. El estudio del tiroides y de los principios arsenicales, justificó la idea de que el organismo humano tenía una cantidad limitada de energía, que en la mujer se emplea en los procesos menstruales y de reproducción, mientras que en el hombre influían en la actividad cerebral, remarcando la diferencia de la teoría de las dos esferas, público/ privado, tal como la conocemos hoy día.
} 
restableciera el ciclo menstrual. La mujer, concluye Novoa, no es para el estudio, porque su descendencia será pobre, física y psíquicamente (Novoa Santos1908: 173). Este hecho se explicaba a partir de la teoría del antagonismo cerebro-sexo. Este antagonismo estribaría en la glándula del tiroides y, específicamente, en el compuesto arsenical que produce esta glándula. Según Novoa, este principio químico circulaba por el organismo nutriendo principalmente al cerebro y al aparato reproductor de forma ambivalente, es decir, cuando nutría a uno, el otro quedaba empobrecido, llegando incluso a atrofiarse, de ahí que Novoa afirmara: "existe como una especie de compensación entre el desarrollo de las funciones cerebrales y el de las funciones sexuales, y que todo lo que se hace a favor de uno de ambos factores, es en detrimento del otro" (Novoa Santos 1908: 112). Este tipo de supuestos y teorías hacía confiar al autor en que el desarrollo de la química fisiológica, aún en fase inicial en esos momentos, ofrecería argumentos indiscutibles para sentar y probar las diferencias entre los sexos.

Siguiendo los trabajos de P. J. Moebius, el catedrático de patología general y autor famoso del libro La inferioridad mental de la mujer, publicado en $1900^{8}$, y las tesis de los evolucionistas, Novoa Santos también sentenció que la pobreza mental de la mujer no era sólo un hecho real, sino necesario: "la pobre mentalidad de la mujer es un hecho psico-fisiológico dependiente de la función perpetuadora de la especie" (Novoa Santos 1908: 114). Novoa encontraba un buen ejemplo de su tesis en las diferencias anatómicas entre las mujeres del campo y las mujeres de la ciudad. Las primeras tenían unas mamas más desarrolladas, en comparación con las mujeres de la ciudad. Esto se debía a que la mujer de ciudad, sobre todo de clase media, consagraba su juventud al estudio, favoreciendo su desarrollo cerebral en detrimento de su aparato genital. En esto coincide con Moebius, quien afirmaba que la difusión de la cultura estaba en relación

\footnotetext{
${ }^{8}$ Como señala la traductora de esta obra, Franca Ongaro Basaglia, en la introducción ( XII-XIII), la obra hay que situarla en el contexto social y político en el que se desarrolla el trabajo de Moebius: a partir de la segunda mitad del siglo XIX las mujeres entran masivamente en el mercado de trabajo; más explotadas que los hombres, comienzan a luchar por la igualdad salarial, el acceso a la instrucción y por el sufragio: la conquista de los derechos negados. Stuart Mill, las sufragistas, las luchas de obreras, las ligas de braceras, voces femeninas diversas incitan a la lucha y a la conquista de los propios derechos. Una nueva conciencia política se está formando entre las mujeres. En este contexto se insertan las voces de Moebius y Lombroso para oponerse a la insubordinación de la mujer (Moebius 1900).
} 
con el decrecimiento de la fecundidad, y admitía el antagonismo entre la función cerebral y sexual estableciendo que "el mayor vuelo de cualquiera de ellas se hace en detrimento de la actividad de la otra" (Novoa Santos 1908: 114). Por tanto, tanto Moebius como Novoa Santos concluyen que el fin natural de la mujer es perpetuar la especie dada su condición biológica.

Los evolucionistas coincidían claramente en estas tesis y abordaron el denominado problema de la mujer desde la teoría de la recapitulación, según la cual la ontogénesis recapitula la filogénesis, es decir, cada individuo en su crecimiento y desarrollo pasaría por las diferentes etapas por las que había evolucionada la especie. O dicho de otra forma, cada organismo individual reproduciría durante su vida la historia de su especie. Esta teoría tuvo nefastas consecuencias en las argumentaciones acerca de la inferioridad evolutiva de las mujeres, ya que fueron presentadas desde la ontogenia como eternas niñas, y desde la filogenia como el eslabón anterior al desarrollo del hombre blanco. Las mujeres estaban para los evolucionistas más cerca de las civilizaciones anteriores que de la propia. Los conceptos de atavismo y degeneración fueron asociados a la inferioridad femenina. El psiquiatra francés Moret (cit. en Aresti 2001: 56 y ss) postuló que la naturaleza podía fallar en su hacer y reproducción de la historia de la especie, generando individuos no acordes con su tiempo, esto es, desfasados, correspondientes a momentos históricos diferentes. La naturaleza, pues, también se podía equivocar, dando lugar a seres atávicos o degenerados, como era claramente el caso de las mujeres. La escala evolutiva mostraba y daba cuenta del avance hacia formas superiores: las mujeres llegaban a un techo evolutivo, eran más genéricas y, por tanto, estaban emparentadas con escalafones evolutivos inferiores, antepasados, otras razas menos desarrolladas eincluso los primates ${ }^{9}$. Las mujeres que no cumplían con las expectativas científicas eran tachadas de degeneradas o atávicas. Y teniendo en cuenta que la naturaleza es un amo inflexible que castiga con penas duras a sus infractores, las mujeres que renegaban de su destino se masculinizaban y

\footnotetext{
${ }^{9}$ La teoría de la recapitulación se inicia con la teoría de la evolución de Darwin, aunque es mayormente desarrollada por E. Haeckel. Asimismo los términos de atavismo y degeneración se incorporaron a estos postulados gracias al psiquiatra B. Moret. Para un desarrollo pormenorizado de esta cuestión véase, (Gómez Rodríguez 2004) y Gómez Rodríguez, Amparo (2003: 28-46).
} 
degeneraban. En consecuencia, como sentenciaba Roberto Novoa: "la originalidad, siempre morbosa, de la hembra, supone una desventaja, en tanto que ella es la encargada de nutrir al nuevo ser. La originalidad femenina perjudica la conservación, la belleza y el vigor de la especie" (Novoa Santos 1908: 120).

En todos estos estudios el modus operandi de la ciencia decimonónica se basó en tres aspectos: a) toda hipótesis acerca de la inferioridad se fundamentaba en una estimable base empírica; b) existía una enorme variabilidad de ideas científicas que podían usarse para justificar argumentos totalmente opuestos, y c) las evidencias cotidianas se convirtieron también en recursos que se sumaban a la autoridad de la ciencia para justificar la indigencia mental y física de las mujeres ${ }^{10}$. Tres son las causas señaladas por Nerea Aresti (2001: 35) para justificar el viraje que se produjo hacia posiciones más conservadoras y tajantes en el contexto de implosión científica: en primer lugar, los prejuicios sexistas de los científicos; en un segundo plano, los temores masculinos ante una desestabilización del orden sexual establecido y, finalmente, la lógica del discurso positivista y la importancia otorgada al avance científico y a la ciencia.

La ciencia, como recurso ideológico, ayudó a configurar un panorama negro para las mujeres de la época. El filtro misógino-cientifista depuró el ideal de mujer por medio de una óptica sexista que reformuló en un lenguaje científico meros prejuicios sexistas. Ello constituyó un núcleo duro, difícil de rebatir, aún a pesar de los esfuerzos de varios y varias intelectuales del momento.

\section{La respuesta feminista}

Algunas autoras españolas ofrecieron respuestas a la concepción de la mujer como ser atávico, desviado, incompleto, determinado biológicamente $\mathrm{y}$, en

\footnotetext{
${ }^{10}$ A modo de ejemplo, el albinismo se consideraba una tara, signo de flaqueza femenina, ya que las diferencias cromáticas expresaban el poder y perfeccionamiento masculino (cit. en Aresti 2001: 56).
} 
consecuencia, evolutivamente inferior. Aunque en España las reacciones contra la fundamentación cientifista de la inferioridad femenina no fueron abundantes, cabe destacar las respuestas de intelectuales que desarrollaban un pensamiento igualitario y un incipiente pensamiento feminista, como Emilia Pardo Bazán y Concepción Arenal ${ }^{11}$. La primera realizó una crítica del evolucionismo, mientras que la segunda se centró en contrarrestar y mostrar las inconsistencias de las teorías fisiológicas sobre la inferioridad de la mujer.

En su ensayo "Reflexiones científicas contra el darwinismo", publicado en 1877, Pardo Bazán planteaba críticas al arraigado pensamiento evolucionista o transformista que incide de forma directa sobre la concepción de la mujer, especialmente a las posiciones de Spencer, cuyo sello lamarkiano era evidente. Su crítica se basaba en rechazar la teoría de la evolución desde planteamientos católicos. Así, Pardo Bazán rechazaba la idea evolucionista de que la especie humana evoluciona desde formas inferiores hacia formas superiores, y en esa evolución los humanos se diferencian en sus funciones y actuaciones, dando lugar a individuos más evolucionados, lo cual conforma la escala evolutiva basada en la selección natural del más fuerte y apto. Pardo Bazán no compartía la equiparación del hombre a las demás especies animales, puesto que el hombre "ya se cubra con la librea de la civilización, ya pinte en sus desnudas carnes los jeroglíficos del salvaje, es siempre un ser aparte de todos los demás seres" (Pardo Bazán 1973: 552) ${ }^{12}$. No compartía pues, la autora, la idea de un antepasado común para el surgimiento de los antropoides: para ella, el hombre no se asemejaba en nada a los

11 Emilia Pardo Bazán (1851-1921), prolífica escritora y novelista gallega, precursora en las reivindicaciones por la igualdad de los sexos, fue la encargada de introducir el naturalismo en España. Además, fue la primera mujer que llegó a la dirección del Ateneo de Madrid en 1906 y, diez años después, la primera en ocupar una cátedra de literaturas neolatinas en la Universidad Central de Madrid, con la que no tuvo mucho éxito entre sus estudiantes, educados en una cultura androcéntrica e incapaz de contemplar a una mujer como docente. Asimismo, fue rechazada su candidatura para formar parte de la Real Academia de la Lengua en tres ocasiones. A Concepción Arenal (1820-1893) se la puede considerar la voz que clama en el desierto, al igual que el título de una de sus obras. Heterodoxa e inagotable ensayista, su pensamiento se orientó a una finalidad clara en lo que a la libertad de la mujer respecta, teorizó y reivindicó para la mujer la necesidad de participar en la educación e instrucción que le permitiera el acceso a un trabajo lucrativo, y le facilitara ser autosuficiente, demandando también la igualdad jurídica, social, salarial y educativa, porque, según sus palabras: “[...] si la mujer tiene deberes que cumplir, derechos que reclamar, benevolencia que ejercer, nos parece que entre su educación y la del hombre no debe haber diferencias" (Arenal 1974: 62). Véase a este respecto, para más información: Cabrera Bosch (2007), Díaz Marcos (2012) y Lacalzada de Mateo (1994).

${ }^{12}$ La primera edición de este artículo data de 1877. 
animales superiores. No existiría, por tanto, un antepasado común e intermedio entre el hombre y los monos superiores. De hecho, según Pardo Bazán, no se habrían encontrado vestigios de este antepasado común, ni ningún tipo de rastro: "Con añadir que en todo el globo no se encuentra rastro, despojo o indicio de este ser, no menos soñado que el hipogrifo, el centauro y la quimera, sobrará cualquier comentario" (Pardo Bazán 1973: 558). Para Pardo Bazán, el evolucionismo era un conjunto de hipótesis y sistemas dependientes de cada pensador que se creía darwinista, con unas enormes pretensiones de explicarlo todo: "La gravitación no dejó nunca los dominios de la física para entrarse por los de la metafísica; el darwinismo, más ambicioso, todo lo invade y pretende explicarlo todo" (Pardo Bazán 1973: 538).

Pardo Bazán se oponía al supuesto del darwinismo social tan apreciado por Spencer (de naturaleza malthusiana), que aseguraba la conservación del individuo más fuerte y mejor, descartando al más débil, y pretendía rebatirlo desde la afirmación constatable de que, aún a pesar de darse una selección continua, los resultados no revelaban que se perpetuase lo mejor, sino más bien lo que se puede. Argüía, en este sentido, el ejemplo de los pequeños organismos que subsisten en condiciones y espacios inaccesibles para los organismos superiores y destacaba cómo estos organismos más evolucionados tienen unas condiciones menos favorecedoras: enfermedades varias, fecundidad escasa, difícil alumbramiento, etc. Asimismo, la ayuda de la selección artificial a manos del hombre tampoco ayudaría a solventar sus vicisitudes: "puede el hombre llevar ventaja en su lucha contra los grandes carniceros y hacer, por medio de la domesticidad, que una especie selvática y feroz, como el perro, llegue a ser su más fiel aliado; pero su destreza es inútil para eliminar o modificar seres más ínfimos" (Pardo Bazán 1973: 547). De esta manera, Pardo Bazán incidía en la contradicción de que si la evolución tendía a lo mejor, y lo mejor era el hombre y su inteligencia, ¿cómo era entonces posible que continuasen existiendo aquellos parásitos y especies inferiores que entorpecían el perfeccionamiento incesante del ser más evolucionado?: "Enfadosos parásitos se albergan en el cuerpo humano; voraces larvas devoran los frutos que el hombre cultiva; la triquina roe nuestras vísceras; la filoxera devasta nuestras 
cosechas, y a pesar de muchas e inteligentes precauciones, no acabamos con estos liliputienses enemigos” (Pardo Bazán 1973: 546-547).

La selección artificial, al igual que la natural, por tanto, sería tan poderosa para suprimir organismos superiores como impotente para erradicar los de menor cuantía que frenaban la escala evolutiva. La continuidad y el perfeccionamiento se repelerían desde la visión de Pardo Bazán: "la marcha de la naturaleza se asemeja a la labor de Penélope o al castigo de Sísifo" (Pardo Bazán 1973: 548). La teoría evolucionista, según la autora, hacía de su interés e imaginación fuente de hechos supuestamente constatables y “conforme a las consecuencias que necesitaba sacar el darwinismo" (Pardo Bazán 1973: 552). Así pues, si la herencia era una aliada del progreso, perpetuando lo mejor, no se entendía, según Pardo Bazán, cómo se perpetuaban y heredaban en muchas ocasiones predisposiciones molestas que no ayudaban al perfeccionamiento. En este sentido, ponía el ejemplo de la ceguera o de las enfermedades del hígado, que, a pesar de la evolución, continuaban perpetuándose entre generaciones. La adaptación al medio también era puesta en entredicho desde el propio postulado del progreso. Para nuestra pensadora la facultad de ponerse en armonía con el medio no era síntoma de progreso, sino más bien de conservación y estabilidad, porque lo que hacía era equilibrar las condiciones de los organismos con el medio exterior. Esto podía ser considerado un progreso relativo, ya que si las condiciones externas cambiasen, la adaptación previa del organismo sería perjudicial. Más que progreso, Pardo Bazán entendía por "adaptación al medio" la sujeción a la necesidad y la lidia con las circunstancias. Y, por todo ello, consideraba que: "la adaptación, lejos de modificar para perfeccionar, sólo modifica para conservar: conclusión bien diversa de la que sostiene el transformismo" (Pardo Bazán 1973: 552). En esta misma línea, la ley biogenética, ${ }^{13}$ que gozó de gran popularidad e importancia en las esferas científicas, también recibió comentarios de la condesa. A grandes rasgos, puede resumirse esta ley en la idea, antes señalada, de que la ontogenia recapitula la filogenia, es decir, cada individuo repite en su historia particular la historia de la

\footnotetext{
${ }^{13}$ Tesis desarrollada por Haeckel en 1866. De gran éxito en su momento, y de la que cabe resaltar la idea de que la naturaleza de la mujer era menos específica y más uniforme, la ontogénesis mostraba que las mujeres estaban más cerca de los antepasados de la especie -primates-, mientras que en la filogénesis, tanto mujeres como salvajes ocupaban el rol del niño. Eran ejemplo de las etapas previas al desarrollo que alcanza el hombre blanco.
} 
evolución de su especie. Para Pardo Bazán, esta formulación de Haeckel no tenía apoyo científico claro y distinto, era más bien una presunción aventurada que explicaba lo conocido por lo ignorado sin que existiesen pruebas empíricas en la naturaleza que corroborasen las tesis de una evolución filogenética. Estos postulados eran expuestos por Pardo Bazán como saltos y libertades en las deducciones, lo que suponía un proceder funesto para el desarrollo de la ciencia (Pardo Bazán 1973: 554).

Con este escrito nuestra autora manifestaba su rechazo a los supuestos ad hoc que los hombres de ciencia presentaban, sobre todo en el caso del darwinismo y las tesis de Haeckel. En este sentido, afirmaba que no hay reproche más grave para una teoría científica, que se pretende rigurosamente experimental, que aquel que señala que mantiene supuestos gratuitos prescindiendo de los hechos y desatendiendo el propio método positivo, como ocurría en el caso del evolucionismo. Como se puede observar tras el acercamiento a los postulados de esta autora, no está haciendo una crítica únicamente desde su sentir cristiano, sino también como mujer intelectual que se encontraba al corriente de los desarrollos y teorías científicas del momento. Finalmente, merece destacarse de este ensayo la postura antirracista de la autora. Si el transformismo equiparaba a la mujer a los pueblos bárbaros y menos desarrollados, todo ello era producto de la visión que de sí mismos tenían los hombres de ciencia, los cuales, “debemos recordar (...) suelen tomarse a sí por tipo superior, y declarar inferiores las que del suyo apartan” (Pardo Bazán 1973: 561).

La segunda autora que analizamos en este apartado, Concepción Arenal, fue una pensadora y escritora muy prolífica que mantuvo ideas modernas y progresistas respecto a la educación de ambos sexos. Arenal afirmaba que la educación era la mejor arma para combatir las desigualdades sociales del pobre, del obrero, de la mujer y de los presos. Su pensamiento, profundamente reformista, resulta difícil de encasillar políticamente, quizá por la variedad de los temas que trató, así como por el escaso perfil político que presentaba. Sea como fuere, su pensamiento ecléctico se orientaba a una finalidad clara en lo que a la libertad de la mujer se refiere: teorizó y reivindicó para la mujer la participación en la educación e instrucción que le permitiera el acceso a un trabajo lucrativo y le facilitara ser autosuficiente. Demandó también la igualdad 
jurídica, social, salarial y educativa porque, según sus palabras: “[...] si la mujer tiene deberes que cumplir, derechos que reclamar, benevolencia que ejercer, nos parece que entre su educación y la del hombre no debe haber diferencias" (Arenal 1974: 62) ${ }^{14}$.

Asimismo, cabe destacar que Arenal fue una ferviente católica, lo cual no la frenó a la hora de criticar la pasividad y contemplación que se reservaba a la mujer en las Sagradas Escrituras, y también desde el clero de la Iglesia. De hecho, se la considera una heterodoxa dentro de la tradición católica española, aunque paradójicamente fue propuesta por el padre Julio Alarcón y Meléndez como la mejor representante de un feminismo aceptable y, por ende, católico, que luchaba contra los feminismos sin Dios que pretendían instaurar los krausistas como Fernando de Castro (Alarcón y Meléndez, 1908: 35).

Arenal fue también una ferviente defensora de la igualdad fisiológica, física y mental de la mujer frente a las ideas positivistas y las teorías evolucionistas que se fueron introduciendo con virulencia en el contexto español, como se ha comentado. El ordensexual impuesto erapartidario de la dicotomía hombre/mujer, reforzándose con la idea de que la mujer era diferente al hombre y esta diferencia la hacía inferior debido a su destino natural de madre de la especie. El progreso científico no traía aparejado un desarrollo social; era conservador en cuanto a la organización de los sexos, perpetuaba la tradicional y arraigada concepción de la mujer como ángel del hogar. Por todo ello, Arenal sentenciaba: "Es tal la fuerza de la costumbre, que saludamos todas estas injusticias con el nombre de derecho" (Arenal 1974: 105). En el caso concreto de la respuesta a la antropología física, y más concretamente centrándose en la fisiología, Arenal realizaba una crítica directa y concreta, mostrando las contradicciones de la teoría de J. F. Gall, en su escrito "Inferioridad de la mujer, cuestión fisiológica", publicado en 1861 (Arenal 1974: 106).

\footnotetext{
14 Concepción Arenal presentó el texto. La emancipación de la mujer en España en el Congreso Pedagógico de 1892, Sección 5a. Para un desarrollo de esta cuestión, véase: Capel (1986) y Durán y Capel (1986). Esta obra de Arenal, póstumamente compilada, y a la que se hace referencia en este trabajo, presenta varios escritos de diferentes épocas.
} 
J. F. Gall instauró el estudio de las bases materiales del cráneo para, a partir de ellas, saltar a los rasgos psicológicos de los individuos. El cerebro era el órgano de la mente compuesto por diferentes facultades. El tamaño del cerebro de la mujer era inferior al del hombre, y desde aquí se daba un salto cualitativo respecto a las funciones intelectuales de éstas. Según Gall, "El cerebro de la mujer está generalmente menos desarrollado en su parte anterior-superior, y por eso, por lo común, las mujeres tienen la frente más estrecha y menos elevada que los hombres" (Arenal 1974: 107). Asimismo, este fisiólogo sentenciaba que las mujeres tenían una irritabilidad superior a la del hombre, eran más sensibles a la información derivada de los sentidos, y su sistema nervioso era más activo. Hasta este punto, el discurso es muy similar a los tópicos científicos del momento, pero Gall argumenta además a favor del ejercicio como requisito indispensable para poder combinar ideas, objetos, y desarrollar así el pensamiento perfecto del hombre. En este sentido, apelaba al volumen relativo de la masa cerebral, entrando en contradicción consigo mismo. Como señala Arenal, Gall defendía la importancia, no del volumen absoluto del cerebro (cuestión que sí era importante en el estudio de las mujeres), sino la importancia del volumen relativo, dado que si lo que importaba era el tamaño real del cerebro, "el elefante y muchos otros cetáceos serían más inteligentes que el hombre" (Arenal 1974: 110). Arenal señalaba certeramente la contradicción en que incurría Gall, pues si la mujer era menos inteligente que el hombre por tener un cerebro menos voluminoso, no resultaba lógico que para hablar de la inteligencia del varón sí se tuviera en cuenta el volumen relativo de la masa cerebral. En este sentido, resulta especialmente atinado el comentario de Arenal sobre la calidad de la masa cerebral y no a la cantidad: "Apreciando, pues, como se debe, el volumen de la cabeza de la mujer, no de una manera absoluta, sino relativa, ¿resultará menor que la del hombre? Si su cuerpo es menor, ¿no ha de serlo la masa cerebral? (Arenal 1974: 110).

La irritabilidad, como se indicó, se atribuyó a la mujer como característica principal de su activo sistema nervioso, y por tanto, característica también de su inferioridad. En este punto, Arenal volvía a poner de relieve otra aporía del fisiólogo 
Gall. El cerebro necesitaría de la energía de sus funciones para combinar ideas y para llevar a cabo su ejercicio. Según el propio Gall, "La energía de las funciones (del cerebro) no depende solamente del tamaño de los órganos, sino también de su irritabilidad" (Arenal 1974: 108). Por ello, Arenal nuevamente se preguntaba si tal irritabilidad del sistema nervioso de las mujeres no sería sintomática de una actividad cerebral similar a la del hombre, aún a pesar de poseer un cerebro más pequeño. $\mathrm{O}$, dicho de otra manera, si se presuponía que el sistema nervioso femenino era más irritable, ello indicaría que tenía más actividad y, por tanto, “¿no podría hacer el mismo trabajo intelectual (la mujer) con menor volumen?" (Arenal 1974: 109). Por todo ello, Arenal defendía que la diferencia entre mujeres y hombres no era natural, no era orgánica, como querían demostrar científicamente los fisiólogos, antropólogos físicos y frenólogos. Las diferencias intelectivas entre hombres y mujeres no serían diferentes entre las personas que vivían en el campo, ni en aquellos que tenían una educación similar o simplemente carecían de ella; al igual sucedía con los niños y las niñas, que, sin nociones de aritmética, no sabrían contar los unos mejor que las otras. La única diferencia existente entre los sexos era la relativa a la educación, "en la mayor parte de las facultades la mujer es igual al hombre, la diferencia intelectual sólo empieza donde empieza la de la educación” (Arenal 1974: 110).

Las consideraciones y argumentaciones de Concepción Arenal, al igual que las de Pardo Bazán, son sintomáticas de una época marcada por el cientifismo que asfixiaba cualquier intento de contradecir lo que desde la ciencia se afirmaba. Los y las intelectuales del momento, partidarios de la ciencia y del progreso, a la vez que defendían la igualdad educativa y social entre hombres y mujeres, se encontraron en una difícil situación que a su vez activó la crítica y la argumentación en contra del reduccionismo biológico.

\section{A modo de epílogo: ¿Una cierta resignación?}

El pensamiento feminista en sus diversas vertientes tuvo que hacer frente a los retos planteados por las verdades científicas, que avanzaban con gran autoridad 
haciendo tambalear el pensamiento igualitarista. La acción combinada del moderno determinismo biológico y los prejuicios anti-femeninos tradicionales, consolidaron una situación comprometida para las pensadoras que apoyaban la causa feminista. En definitiva, la exclusión de las mujeres del terreno científico, y su valoración como ser humano inferior fue intrínseco al proyecto cientificista desde sus inicios.

La resistencia a compartir el status de ser racional se ha de interpretar en el marco de las relaciones de género, que como se ha venido diciendo, mantuvo el status quo sexual. La fuerza de los principios, las contra argumentaciones y la demanda de coherencia en las tesis postuladas por parte de las feministas citadas, no constituyeron pruebas de peso para aplacar la impronta positivista. El contexto socio-cultural del momento, marcado férreamente por esta ideología, frenó las pocas voces disidentes.

Concepción Arenal constituye un ejemplo de la dificultad de escapar a la presión de tan asfixiante contexto. En 1881, justo dos décadas después de rebatir las tesis fisiológicas de Gall sobre la inferioridad mental de la mujer, concedía que:

(...) no albergamos hoy aquel íntimo convencimiento en la igualdad de la inteligencia de los dos sexos manifestado en La mujer del porvenir. Nuevos hechos observados y una reflexión más detenida nos han inspirado dudas que sinceramente exponemos: la infalibilidad no es cosa que razonablemente nadie deba conceder a otro ni reclamar para sí. (Arenal 1974: 269)

De hecho, ante las irrebatibles verdades de la ciencia, Arenal parecía renunciar a sus aspiraciones de igualdad a favor de alguna forma de reconocimiento:

¿Será la mujer más espontánea y menos reflexiva, adivinará más y observará menos; su acción será más extensa y menos intensa, más perseverante y menos fogosa, con más facultades receptivas y menos poder creador, y tendrá, en fin, una inteligencia que, todo bien apreciado, sea equivalente, pero no igual a la del hombre? (Arenal 1974: 269) 
Carmen de Burgos, Colombine ${ }^{15}$, constituye otro ejemplo de la contradicción en que se movían las feministas del momento. Tras traducir al castellano y prologar la obra de Moebius, adoptaba una actitud resignada ante las tesis inferiorizantes que el libro defendía (Moebius 1900). Resultaba muy difícil para una mujer progresista oponerse a la ciencia, incluso a costa de la subvaloración personal.

El positivismo y el evolucionismo dibujaban un panorama oscuro para las mujeres. La ciencia se erigió como instancia privilegiada para diferenciar lo verdadero de lo falso, también respecto a la superioridad masculina e inferioridad femenina. La ciencia marcó una fractura irreconciliable entre los géneros. La mujer era un individuo de segundo orden que debía ser guiada por la inteligencia y vigor masculinos. Los partidarios de la igualdad no abrieron fisuras en estas ideas con sus críticas, por lo que las pensadoras feministas no constituyeron un rival de interés para los planteamientos cientifistas. Así pues, la emancipación del pensamiento religioso que suponía la ciencia, indicio de modernidad, no incluyó a las mujeres, cuya naturaleza las supeditaba a la superioridad masculina. Las ideas feministas y sus propuestas de cambio para las mujeres no cristalizaron hasta muy tardíamente, con la Segunda República, varias décadas después del periodo en el que se centra este artículo.

\section{Referencias bibliográfícas}

Alarcón y Meléndez, Julio. 1908. Un feminismo aceptable. Madrid: Sucesores de Rivadeneyra.

Arce Pinedo, Rebeca. 2005. "De la mujer social a la mujer azul: la reconstrucción de la feminidad por las derechas españolas durante el primer tercio del siglo XX". Ayer 57, vol. 1: 247-272.

\footnotetext{
${ }^{15}$ Carmen de Burgos Seguí (1867-1932), periodista, traductora, escritora y primera mujer española en ser corresponsal de guerra (Marruecos, 1909), de orientación feminista y republicana, abogó por el papel cultural y social de las mujeres. Fue maestra de Primera Enseñanza desde junio de 1895, luego maestra de Primera Enseñanza Superior desde 1898, y en 1901 obtuvo, por oposición, plaza en la Escuela Normal de Guadalajara, y, finalmente en 1911, en la Normal de Madrid. Publicó y escribió numerosos artículos, libros y novelas, y además colaboró en varios periódicos como El País y $A B C$; además de ser redactora en El Heraldo de Madrid y en el Nuevo Mundo de Madrid. Para una aproximación véase, Castillo Martín (2003).
} 
2007. Dios, patria y hogar. La construcción de la mujer española por el catolicismo y las derechas en el primer tercio del siglo XX. Santander: Ediciones de la Universidad de Cantabria.

Arenal, Concepción. 1974. La emancipación de la mujer en España. Madrid: Biblioteca Júcar.

.2009. La mujer del porvenir. Barcelona: e-litterae. $1^{\text {a }}$ edición 1869.

Aresti, Nerea. 2000. "El ángel del hogar y sus demonios: Ciencia, religión y género en la España del siglo XIX”. Historia contemporánea 21: 363-394.

2001. Médicos, donjuanes y mujeres modernas. Los ideales de feminidad y masculinidad en el primer tercio del S. XX. Bilbao: Servicio editorial del País Vasco.

2012. "Los argumentos de la exclusión. Mujeres y liberalismo en la España contemporánea". Historia constitucional: Revista Electrónica de Historia Constitucional 13: 407-431.

Capel, Rosa Ma . 1986. "La apertura del horizonte cultural femenino: Fernando de Castro y los congresos pedagógicos del siglo XIX". 1986. Mujer y sociedad en España (1700-1975). Eds M ${ }^{\mathrm{a}}$ Ángeles Durán y Rosa María Capel. Madrid: Ministerio de Cultura.

Cabrera Bosch, $\mathrm{M}^{\mathrm{a}}$ Isabel. 2007. "Las mujeres que lucharon solas: Concepción Arenal y Emilia Pardo Bazán”. El feminismo en España: Dos siglos de historia. Coord. Pilar Folguera Crespo. Madrid: Editorial Pablo Iglesias: 45-80.

Castillo Martín, Marcía. 2003. Carmen de Burgos (1867-1932). Colombine. Madrid: Ediciones del Orto.

De la Revilla. 1879. "La emancipación de la mujer". Revista Contemporánea. Año IIIIV. Tomo XVIII: 447-463.

Díaz Marcos, Ana M. 2012. Salirse del tiesto. Ensayistas españolas, feminismo y emancipación (1861-1923). Oviedo: KRK Ediciones.

Gall, Joseph. F. 1810-1819. Anatomie et physiologie du systeme nerveux (4 vols.). París: Shoell.

Gimeno de Flaquer, Concepción: "El problema Feminista", conferencia en el Ateneo de Madrid. Fuente: Biblioteca Nacional de España.

Gómez Rodríguez, Amparo. 2003. Filosofía y metodología de las ciencias sociales. Madrid: Alianza Editorial.

2004. La estirpe maldita. La construcción científica de lo femenino. Madrid: Minerva Ediciones. 
González Blanco, Edmundo. 1905. "La inferioridad mental de la mujer". Nuestro Tiempo 61, vol. III: 12-35.

Lacalzada de Mateo, M. J. 1994. La otra mitad del género humano: la panorámica vista por Concepción Arenal (1820-1893). Málaga: Atenea, Estudios de la Universidad de Málaga.

Mariscal y García, Nicasio. 1898. Ensayo de una higiene de la inteligencia. Madrid: Imprenta de Ricardo Rojas.

Moebius, Paul, J. 1900. La inferioridad mental de la mujer. Valencia: Impresiones de El Pueblo.

Nash, Mary. 1999. Rojas: Las mujeres republicanas. Madrid: Taurus.

. 2006. "Identidades de género, mecanismos de subalternidad y procesos de emancipación femenina”. CIDOB d'afers internacionals: 73-74.

http://dialnet.

unirioja.es/servlet/busquedadoc?t=\%E2\%80\%9CIdentidades $+\mathrm{de}+\mathrm{g} \% \mathrm{C} 3 \%$ A9nero $\% 2 \mathrm{C}+$ mecanismos+de+subalternidad $+\mathrm{y}+$ procesos+de+\%09emancipaci\%C3\%B3n + femenina\%E2\%80\%9D\&db=1\&td=todo [ noviembre 2013]

Novoa Santos, Roberto. 1908. La indigencia espiritual del sexo femenino. Las pruebas anatómicas, fisiológicas y psicológicas de la pobreza mental de la mujer. Su explicación biológica. Madrid: Sempere y Compañía.

Nordau, Max. 1901. Psico-fisiología del genio y del talento. Madrid: Sáenz de Jubera.

Pardo Bazán, Emilia. 1973. "Reflexiones científicas contra el darwinismo". Obras Completas, Madrid: Aguilar.

Spencer, Herbert. 1871 [1855]. Synthetic Philosophy. The Principles of Psychology. Nueva York: D. Applenton.

Tacoronte Domínguez, M. J. 2013. "La biopolítica española: el caso de Roberto Novoa Santos”. Estudios políticos de la ciencia. Políticas y desarrollo científico en el siglo XX. Eds. Ámparo Gómez Rodríguez y Antonio Francisco Canales Serrano. Madrid: Plaza y Valdés Editores. 125-142. 